\title{
Resource recovery using whey permeate to cultivate Phellinus linteus mycelium: Solid-state and submerged liquid fermentation
}

\author{
Kyungjin Cho, ${ }^{*}$ Joonyeob Lee, $†$ Gyuseong Han, $†$ Na Kyung Kim, $\ddagger$ Hyokwan Bae, ${ }^{*}$ and Seokhwan Hwang ${ }^{1}$ \\ ${ }^{*}$ Center for Water Resource Cycle Research, Korea Institute of Science and Technology, 39-1 Hawolgok-Dong, Seongbuk-Gu, Seoul 136-791, \\ Republic of Korea \\ †School of Environmental Science and Engineering, Pohang University of Science and Technology (POSTECH), Pohang, Gyeongbuk 790-784, \\ Republic of Korea \\ ‡Department of Civil and Environmental Engineering, University of Illinois at Urbana-Champaign, 205 North Mathews Ave., Urbana 61801
}

\begin{abstract}
The growth characteristics of Phellinus linteus mycelium were assessed and compared under solid-state fermentation (SSF) and submerged liquid fermentation (SLF) systems on whey permeate medium. Response surface methodology was used to investigate the growth rates of mycelia under various conditions of operating temperature $\left(T_{\mathrm{O}}\right)$, initial $\mathrm{pH}$, and substrate concentration $([S])$. The optimal growth conditions of P. linteus mycelium were determined to be $26.1^{\circ} \mathrm{C}, \mathrm{pH} 4.6$, and $60.3 \mathrm{~g}$ of lactose/L in the $\mathrm{SSF}$ system, and $29.0^{\circ} \mathrm{C}, \mathrm{pH}$ 5.0 , and $65.3 \mathrm{~g}$ of lactose/L in the SLF system. The maximum growth rates were predicted to be $1.92 \pm$ $0.01 \mathrm{~mm} / \mathrm{d}$ in $\mathrm{SSF}$ and $192.1 \pm 0.0 \mathrm{mg} / \mathrm{L}$ per day in SLF. Random trials were conducted to experimentally validate the evaluated optimal conditions. The differences between the modeled and observed values were only $5.3 \%$ in the SSF system and $6.1 \%$ in the SLF system. Significant engineering factors differed between the fermentation techniques; $T_{\mathrm{O}}$ was significant in both cultivation systems, whereas initial $\mathrm{pH}$ was significant in SSF but $[S]$ was significant in SLF. Our findings can be used to guide the operation of the bioconversion process for cultivating $P$. linteus mycelium using whey permeate wastewater.
\end{abstract}

Key words: whey permeate wastewater, Phellinus linteus, response surface methodology, bioconversion

\section{INTRODUCTION}

Whey is a liquid by-product of cheese production, and world production of cheese whey is currently more than $145,000,000$ tonnes per year and is increasing (Pais et al., 2014). The whey is filtered to recover whey proteins,

Received March 26, 2015.

Accepted June 12, 2015.

${ }^{1}$ Corresponding author: shwang@postech.ac.kr and the final waste of this process is whey permeate, which consists of small molecules such as lactose and mineral salts (Dallas et al., 2014). Disposal of this dairy wastewater causes serious environmental problems due to its high chemical oxygen demand (COD) and large volume (Song et al., 2007). However, whey permeate wastewater is regarded as a nutritionally valuable resource for microbial growth because it contains nutrients such as nitrogen and trace elements. In fact, the potential of using whey wastewater as a substrate for diverse bioconversion processes such as anaerobic digestion and bio-ethanol production has been demonstrated (Sansonetti et al., 2009; Carvalho et al., 2013). However, whey wastewater is not an ideal substrate for anaerobic digestion because the acidic $\mathrm{pH}$ and highly biodegradable content of the wastewater result in rapid acidification (Diamantis et al., 2014). In addition, use of whey permeate for bio-ethanol production is not currently feasible because microorganisms that efficiently ferment lactose to bio-ethanol are not available (Akbas et al., 2014). Therefore, efficient utilization of the nutrient resources in whey permeate wastewater requires development of a more appropriate bioprocess that can stably produce economically valuable commodities; we suggest using it to cultivate Phellinus linteus mycelia.

Phellinus linteus is a medicinal basidiomycete (mushroom) that has been used as a traditional treatment for gastroenteric dysfunction, diarrhea, and hemorrhage, and that may have anticancer properties (Mei et al., 2015). Fruiting bodies of $P$. linteus are very expensive because their production is complicated and takes 5 to 6 mo (Lee et al., 2011). However, the beneficial bioactive compounds of mushrooms can be extracted directly from the mycelia, so cultivation time can be reduced (Hatvani and Mećs, 2001). Therefore, if $P$. linteus mycelia can be successfully grown in whey permeate wastewater, economic benefits could be achieved by producing valuable products while reducing the amount of organic waste. In addition, bioconversion of $P$. linteus from the wastewater can be a suitable bio- 
process strategy because fungi tolerate acidic $\mathrm{pH}$ better than do bacterial communities (Carvalho et al., 2013). However, use of $P$. linteus mycelia for this process requires information on how various parameters affect its growth characteristics.

Two fermentation techniques, solid-state fermentation (SSF) and submerged liquid fermentation (SLF), have been used to cultivate mycelia. The 2 systems have unique advantages and disadvantages. Solidstate fermentation refers to any fermentation process in which microorganisms grow on a water-insoluble solid substrate in the absence of water flow (Liang et al., 2009); SSF has been used to produce high-value products such as enzymes from mycelia (Singhania et al., 2009). It uses a small fermentation volume and allows easy separation of byproducts, so it costs little to install and operate (Shuler and Kargi, 2001). However, scale-up of SSF system operations is complicated by the difficulty in monitoring and controlling factors such as operating temperature $\left(\boldsymbol{T}_{\mathbf{O}}\right)$ and $\mathrm{pH}$.

Submerged liquid fermentation refers to fermentation in an aqueous medium; SLF has been applied to mass production of mycelia (Singhania et al., 2009). A crucial advantage of SLF is that it provides good mixing conditions during bioprocess operation. The mixing ensures homogeneity of various factors such as dissolved oxygen, $T_{\mathrm{O}}$, and substrate concentration ([S $]$; Raghavarao et al., 2003). Moreover, the homogeneity enables precise monitoring and efficient control of these factors, so scale-up for mycelial cultivation is easier for SLF than for SSF (Singhania et al., 2009). However, the SLF system is more vulnerable to contamination by bacteria or yeasts than the SSF system because of the high water content in SLF (Shuler and Kargi, 2001). Therefore, a suitable cultivation strategy should be selected according to the cultivation purpose.

Because of the complementary advantages and disadvantages of SSF and SLF, we investigated the growth rate of $P$. linteus grown in SSF and SLF systems on whey permeate wastewater medium, and compared the growth characteristics of the mycelia in the 2 systems. Three engineering factors: $T_{\mathrm{O}}$, initial $\mathrm{pH}$, and $[S]$ were considered the independent variables for the statistical test. The significant engineering factors were evaluated by ANOVA.

\section{MATERIALS AND METHODS}

\section{Microorganism}

Phellinus linteus (KCTC 6719) was obtained from the Korean Collection for Type Cultures (KCTC; Daejeon, Korea) and maintained in a potato dextrose agar slant at $4^{\circ} \mathrm{C}$. This seed culture of $P$. linteus was transferred into petri dishes filled with potato dextrose agar medium and incubated at $25^{\circ} \mathrm{C}$ for $4 \mathrm{~d}$. After incubation, as an inoculum for subsequent experiments, an active site of the mycelial agar disk with 5-mm diameter was excised using a sterilized round cutter.

\section{Whey Permeate Wastewater}

Dried whey permeate powder was obtained from Gossner's cheese plant (Logan, UT). To provide practical operating information for the application in a commercial plant, the whey permeate was used as the sole substrate (Table 1). The whey permeate powder was dissolved in distilled water to obtain different $[S]$ for subsequent experiments (Table 2); $[S]$ was adjusted based on lactose content because lactose was the primary carbon source of whey permeate wastewater.

For SSF, the whey permeate powder was dissolved in a $250-\mathrm{mL}$ flask with several target $[S]$ (Table 2). At that point, commercial agar (Becton Dickinson and Co., Sparks, MD) was added ( $1.5 \% \mathrm{wt} / \mathrm{vol})$ to the flask to solidify the whey permeate wastewater. The $\mathrm{pH}$ was adjusted by using $2 \mathrm{~N} \mathrm{HCl}$ or $2 \mathrm{~N} \mathrm{NaOH}$ to meet the experimental conditions, and the medium was sterilized by autoclaving at $121^{\circ} \mathrm{C}$ for $20 \mathrm{~min}$ (Table 2). The sterilized solution was poured into petri dishes, allowed to solidify, and then used as the medium for cultivation of $P$. linteus mycelium. The whey permeate wastewater was prepared in the same for SLF as for SSF except for the solidification step.

\section{SSF and SLF}

Solid-state fermentation was conducted in petri dishes. A mycelial agar disk was transferred to the center of each dish and the dishes were incubated at different $T_{\mathrm{O}}$ according to the experimental design (Table 2 ). The radial extension of the mycelium was monitored every $24 \mathrm{~h}$ for $30 \mathrm{~d}$ to evaluate the growth rate, because the colony grows in a circular fashion (Lee et al., 2008b). The radius was measured using a laboratory calipers at 4 different positions and averaged. The slope of the linear regression of radius over time (i.e., the average radial extension rate) was regarded as the mycelial growth rate under the given condition.

Submerged liquid fermentation was conducted in 250$\mathrm{mL}$ Erlenmeyer flasks with $100-\mathrm{mL}$ working volume. Five mycelial discs were inoculated into each flask, and the flasks were incubated at different $T_{\mathrm{O}}$ with 100-rpm agitation (Table 2). The mycelial growth rate in the SLF system was evaluated by measuring the concentration of volatile suspended solids (VSS). The VSS 
Table 1. Characteristics of whey permeate wastewater ( $1 \mathrm{~g}$ of whey permeate powder/L of water)

\begin{tabular}{|c|c|c|c|c|}
\hline \multirow[b]{2}{*}{ Classification } & \multirow{2}{*}{\multicolumn{2}{|c|}{$\begin{array}{l}\text { Measurement } \\
\text { parameter }^{1}\end{array}$}} & \multicolumn{2}{|c|}{ Concentration $(\mathrm{mg} / \mathrm{L})$} \\
\hline & & & Mean & SD \\
\hline \multirow[t]{6}{*}{ Solids } & \multicolumn{2}{|l|}{ TS } & 1,074 & 39 \\
\hline & \multicolumn{2}{|l|}{ TSS } & 41 & 3 \\
\hline & \multicolumn{2}{|l|}{ TDS } & 1,032 & 41 \\
\hline & \multicolumn{2}{|l|}{ VS } & 929 & 29 \\
\hline & \multicolumn{2}{|l|}{ VSS } & 35 & 7 \\
\hline & \multicolumn{2}{|c|}{ VDS } & 894 & 35 \\
\hline \multirow[t]{4}{*}{ Organic nutrients } & \multicolumn{2}{|c|}{ Total COD } & 957 & 11 \\
\hline & \multicolumn{2}{|c|}{ Soluble COD } & 945 & 15 \\
\hline & \multicolumn{2}{|c|}{ Total carbohydrate } & 883 & 77 \\
\hline & \multirow{6}{*}{$\begin{array}{l}\text { Lactose } \\
\text { Cation }\end{array}$} & & 691 & 16 \\
\hline \multirow[t]{10}{*}{ Ions } & & $\mathrm{Na}^{+}$ & 12.1 & 0.5 \\
\hline & & $\mathrm{NH}_{4}^{+}$ & 1.5 & 0.4 \\
\hline & & $\mathrm{K}^{+}$ & 42.4 & 0.0 \\
\hline & & $\mathrm{Mg}^{2+}$ & 1.9 & 0.0 \\
\hline & & $\mathrm{Ca}^{2+}$ & 5.4 & 1.0 \\
\hline & \multirow[t]{5}{*}{ Anion } & $\mathrm{Cl}^{-}$ & 27.2 & 0.0 \\
\hline & & $\mathrm{NO}_{2}^{-}$ & 0.2 & 1.0 \\
\hline & & $\mathrm{NO}_{3}^{-}$ & 1.6 & 0.0 \\
\hline & & $\mathrm{PO}_{4}{ }^{3-}$ & 20.5 & 0.0 \\
\hline & & $\mathrm{SO}_{4}{ }^{2-}$ & 3.1 & 0.4 \\
\hline
\end{tabular}

${ }^{1}$ TSS = total suspension solid; TDS = total dissolved solid; VS = volatile solid; VSS = volatile suspension solid; $\mathrm{VDS}=$ volatile dissolved solid; $\mathrm{COD}=$ chemical oxygen demand.

concentration was a reasonable indicator of the growth of $P$. linteus because $96.1 \%$ of total compounds existed in soluble form in the whey permeate wastewater [i.e., the ratio of total dissolved solid (TDS) to total solid (TS); Table 1]. The increase of mycelial biomass per unit time was considered the mycelial growth rate.

Table 2. Experimental conditions by central composite design and observed growth rates

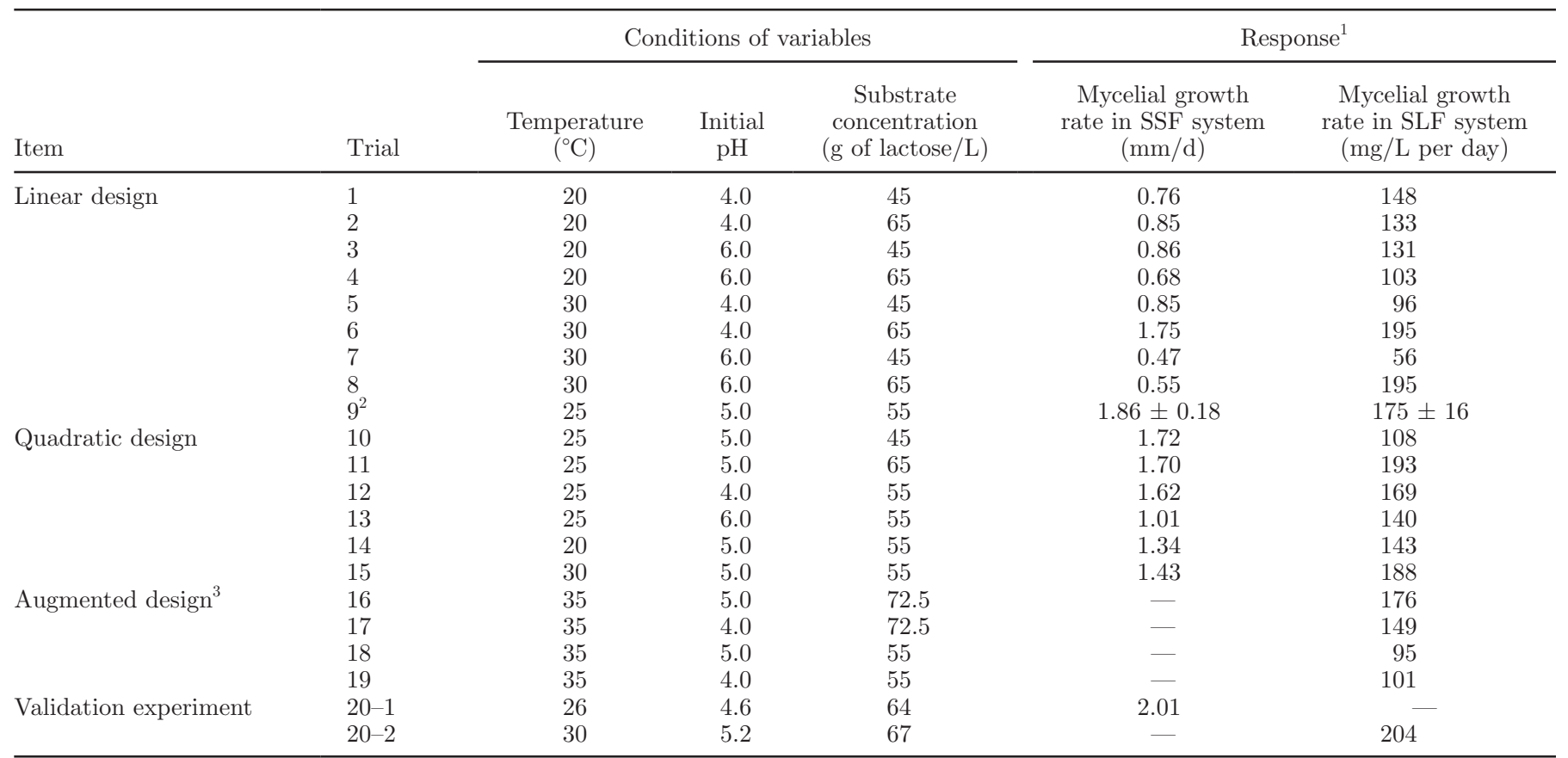

${ }^{1} \mathrm{SSF}=$ solid-state fermentation; SLF = submerged liquid fermentation.

${ }^{2}$ Center point (mean $\pm \mathrm{SD}, \mathrm{n}=5$ ).

${ }^{3}$ Augmented trials were only performed for the SLF system to find optimum growth conditions. 


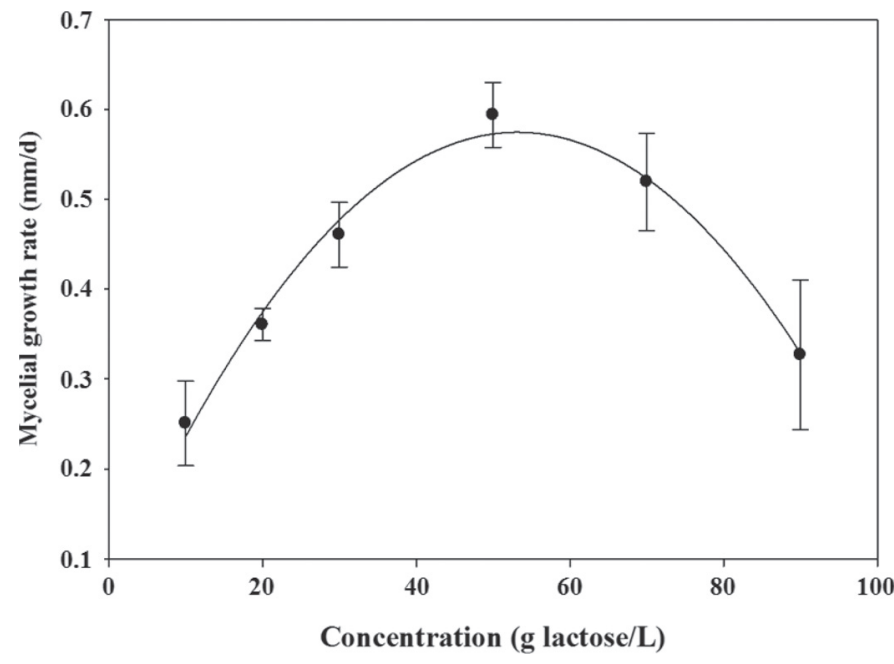

Figure 1. Observed and predicted mycelial growth rates of Phellinus linteus at different whey permeate concentrations based on the lactose content. $\bullet=$ observed mycelial growth rates; solid line = model predictions; error bars indicate standard deviation; $\mathrm{n}=8$ at each condition.

\section{Experimental Design for Response Surface Methodology}

Response surface methodology (RSM) was used to evaluate the simultaneous effects of $T_{\mathrm{O}}$, initial $\mathrm{pH}$, and $[S]$ on the growth rate of $P$. linteus utilizing whey permeate wastewater. The experimental design was conducted based on a central composite in cube design with a center point replicated 5 times (Lee et al., 2008a). This type of experimental design is useful to minimize the number of experimental trials required to obtain statistically significant results under given conditions. The experimental conditions for RSM were set at $20 \leq T_{\mathrm{O}} \leq 30^{\circ} \mathrm{C}$ and $4.0 \leq$ initial $\mathrm{pH} \leq 6.0$ based on the growth characteristics of $P$. linteus in previous studies (Hwang et al., 2003; Lee et al., 2008b, 2011). Preliminary experiments were conducted at different $[S]$ (i.e., 10, 20, 30, 5070 , and $90 \mathrm{~g}$ of lactose/L) at $\mathrm{pH} 5.5$ and $25^{\circ} \mathrm{C}$ to determine the experimental range because information about the effects of $[S]$ on growth of $P$. linteus in whey permeate wastewater medium is very limited. After using the least squares method to estimate polynomials, the adequacy of the models was checked by inspecting residual plots and by considering statistical values. Additional trials were conducted under random conditions to verify the statistical model for each cultivation system experimentally.

\section{Analytical Methods}

Lactose concentration was analyzed using an HPLC [Agilent Technologies, Palo Alto, CA; RI detector; Supel- cosil LC-NH $\mathrm{N}_{2}$ chromatographic column (Supelco, Bellefonte, PA); $5 \mu \mathrm{m}, 250 \mathrm{~mm} \times 4.6 \mathrm{~mm}$; acetonitrile: $\mathrm{H}_{2} \mathrm{O}$ (83:17) as a mobile phase]. Chemical oxygen demand and soluble COD (SCOD) concentrations were measured using colorimetry. Total carbohydrate (TC) concentration was measured using a phenol-sulfuric assay (DuBois et al., 1956). Solid concentrations such as TS, TDS, total suspended solids (TSS), volatile solids (VS), volatile dissolved solids (VDS), and VSS were determined according to the procedures in standard methods (APHA-AWWA-WEF, 2005). Two identical ion chromatographs (790 Personal IC, Metrohm, Herisau, Appenzell Ausserrhoden, Switzerland) were used to measure the concentrations of cations and anions in the samples.

\section{RESULTS}

\section{Characteristics of Whey Permeate Wastewater and Preliminary Test}

Physico-chemical analyses of the whey permeate wastewater were performed (Table 1). The ratio of soluble to total COD was $98.7 \%$; that is, the organic compounds contained in the whey permeate wastewater were mostly soluble. The ratio of lactose to total carbohydrate was $78.3 \%$, confirming that lactose was the primary carbon source. In addition to the high organic contents, the whey permeate wastewater contained various inorganic ingredients, which could support the growth of mycelia (Carvalho et al., 2013).

In the preliminary experiments, the growth rate of $P$. linteus was greatest at $[S] \approx 55.0 \mathrm{~g}$ of lactose $/ \mathrm{L}$; the growth pattern was successfully fit by the Shi model $\left(\mathrm{R}^{2}=0.98\right.$; Shi et al., 1999; Figure 1). Therefore, the center point in the RSM experiment was set at $[S]=$ $55 \mathrm{~g}$ of lactose/L.

\section{Modeling and Analyzing Mycelial Growth Rate in SSF}

Thirteen trials including the center point (trials 1 to 9; Table 2) were run on solid medium. Initially, the data were fit using least squares to a first-order model to access the location of the optimum condition. The $P$-values, correlation coefficient $\mathrm{R}^{2}$, and lack of fit (LOF) were calculated to validate the model adequacy. The linear model had $P=0.79$ and $\mathrm{R}^{2}=0.11$; the LOF was significant at the $1 \% \alpha$-level, suggesting that this model was not statistically significant to describe the mycelial growth rate of $P$. linteus. The interaction model was also statistically insignificant $(P=0.91$, $\left.\mathrm{R}^{2}=0.24\right)$ with LOF that was also significant at $1 \%$ $\alpha$-level. A second- or higher-order model could not be fit using the data from trials 1 to 9 because of the lack 
of axial data points, so 6 additional trials (trials 10 to 15; Table 2) were conducted to collect sufficient data to estimate polynomials that describe the mycelial growth rate. From the results, a quadratic model (Eq. [1]) was adequate $\left(P<0.01, \mathrm{R}^{2}=0.951\right.$, LOF not significant at the $1 \% \alpha$-level $)$ to describe the growth rate $\left(\eta_{1}\right)$ of the mycelial $P$. linteus in the SSF system (Figure 2):

$$
\begin{gathered}
\eta_{1}=1.84+1.1 \times 10^{-2} X_{1}-2.4 \times 10^{-1} X_{2}+8.1 \\
\times 10^{-3} X_{3}-3.8 \times 10^{-2} X_{1} X_{2}+2.7 \times 10^{-3} X_{1} X_{3}-1.4 \\
\times 10^{-2} X_{2} X_{3}-1.7 \times 10^{-2} X_{1}^{2}-4.4 \times 10^{-1} X_{2}^{2} \\
-1.4 \times 10^{-3} X_{3}^{2}
\end{gathered}
$$

where $\eta_{1}=$ mycelial growth rate in the SSF culture $(\mathrm{mm} / \mathrm{d})$ and $X_{\mathrm{i}}=$ independent variable $\mathrm{i}\left[\mathrm{i}=T_{\mathrm{O}}\left({ }^{\circ} \mathrm{C}\right)\right.$, $\mathrm{pH}$, and $[S]$ (g of lactose/L) in order].

The residual plot (Figure 3) demonstrated no patterns or trends, so no weakness of the model was detected (Lee et al., 2011). Using Eq. [1], the optimum growth condition was determined to be $T_{\mathrm{O}}=26.1^{\circ} \mathrm{C}, \mathrm{pH}=4.6$, and $[S]=60.3 \mathrm{~g}$ of lactose/L, at which the predicted $\eta_{1}$ $=1.92 \pm 0.01 \mathrm{~mm} / \mathrm{d}$. The additional trial (trial 20-1 in Table 2) was conducted under random conditions (i.e., $T_{\mathrm{O}}=26.0^{\circ} \mathrm{C}, \mathrm{pH}=4.6,[S]=63.7 \mathrm{~g}$ of lactose $/ \mathrm{L}$ ) to assess the accuracy of the model predictions. The growth rate at this random condition was $2.01 \mathrm{~mm} / \mathrm{d}$, which differed by only $5.3 \%$ from the model response of $1.90 \mathrm{~mm} / \mathrm{d}$, indicating that the model adequately represented the SSF experimental sets. The significance of independent variables was also evaluated through ANOVA. The growth rate of $P$. linteus was significantly affected by $T_{\mathrm{O}}$ and $\mathrm{pH}$ at $1 \% \alpha$-level but was not affected for the values of $[S]$ tested (Table 3 ). The results indicate that $T_{\mathrm{O}}$ and $\mathrm{pH}$ are important engineering factors when SSF is used to cultivate $P$. linteus mycelia in whey permeate wastewater.

\section{Modeling and Analyzing Mycelial Growth Rate in SLF}

Model evaluation for the SLF system was conducted in the same way as for SSF. In SLF, the first-order model was not statistically significant to describe the growth rate of $P$. linteus $(P>0.05$, for linear and interaction model; LOF significant at $5 \% \alpha$-level). Therefore, 6 additional trials (trials 10 to 15; Table 2) were conducted to find the optimum growth conditions. A quadratic equation was adequate $\left(P<0.001, \mathrm{R}^{2}=0.91\right.$; LOF insignificant at $5 \% \mathrm{\alpha}$-level) to describe the relationship. However, the optimal conditions of $T_{\mathrm{O}}$ and $[S]$ (i.e., $T_{\mathrm{O}}$ $=29.0{ }^{\circ} \mathrm{C},[S]=65 \mathrm{~g}$ of lactose $/ \mathrm{L}$ ) were located near the boundary of the experimental design Therefore, the design boundary was expanded to find the optimum growth condition by performing 4 additional trials (trials 16 to 19; Table 2).

Finally, a quadratic model (Eq. [2]) was adequate $\left(P<0.01, \mathrm{R}^{2}=0.874 ;\right.$ LOF not significant at the $\alpha=$ 0.05 level) to describe mycelial growth rate in the SLF system (Figure 4):

$$
\begin{aligned}
\eta_{2}= & 185.4-1.2 X_{1}-6.3 X_{2}+2.3 X_{3}+7.2 \times 10^{-1} X_{1} X_{2} \\
+ & 5.9 \times 10^{-1} X_{1} X_{3}+6.3 \times 10^{-1} X_{2} X_{3}-8.4 \\
& \times 10^{-1} X_{1}^{2}-5.4 X_{2}^{2}-2.4 \times 10^{-1} X_{3}^{2},
\end{aligned}
$$

where $\eta_{2}=$ mycelial growth rate in the SLF culture $\left(\mathrm{mg} / \mathrm{L}\right.$ per day) and $X_{\mathrm{i}}=$ independent variable i [i $=$ $T_{\mathrm{O}}\left({ }^{\circ} \mathrm{C}\right), \mathrm{pH}$, and $[S]$ (g of lactose/L) in order].

The residual plots demonstrated no patterns or trends, so no weakness of the model was detected (Figure 3). Using Eq. [2], the optimal growth condition was determined to be $T_{\mathrm{O}}=29.0^{\circ} \mathrm{C}, \mathrm{pH}=5.0$, and $[S]=65.3$ $\mathrm{g}$ of lactose $/ \mathrm{L}$, at which the predicted $\eta_{2}=192.1 \pm 0.0$ $\mathrm{mg} / \mathrm{L}$ per day. An additional trial was conducted at a random growth condition (i.e., $T_{\mathrm{O}}=30.0^{\circ} \mathrm{C}, \mathrm{pH}=5.2$, $[S]=67.0 \mathrm{~g}$ of lactose $/ \mathrm{L})$ to validate model accuracy (trial 20-2; Table 2). The observed growth rate was $204.0 \mathrm{mg} / \mathrm{L}$ per day, differing by only $6.1 \%$ from the model response of $191.5 \mathrm{mg} / \mathrm{L}$ per day. In addition, $T_{\mathrm{O}}$ and $[S]$ were statistically significant at $1 \% \alpha$-level for the SLF system, whereas $\mathrm{pH}$ were not. The results indicate that $T_{\mathrm{O}}$ and $[S]$ are the crucial engineering factors in the SLF system (Table 3).

\section{DISCUSSION}

Effects of $T_{\mathrm{O}}, \mathrm{pH}$, and $[S]$ on mycelial growth of $P$. linteus were determined in SSF and SLF systems operating with whey permeate wastewater as the sole nutrient source (Figures 2 and 4). The results indicate that whey permeate wastewater can be used as the sole substrate for mycelial growth of P. linteus. However, the optimal growth conditions and the significant factors differed between the SSF and SLF systems.

In both systems, $T_{\mathrm{O}}$ significantly affected mycelial growth rate. Growth rate of the mycelial $P$. linteus was greatest at $T_{\mathrm{O}}=26.1^{\circ} \mathrm{C}$ in the $\mathrm{SSF}$ system and at $T_{\mathrm{O}}=$ $29.0^{\circ} \mathrm{C}$ in the $\mathrm{SLF}$ system. These $T_{\mathrm{O}}$ values are reasonable because $P$. linteus grows optimally in the range of 25.0 to $30.0^{\circ} \mathrm{C}$ (Lee et al., 2003). The optimum $T_{\mathrm{O}}$ of $P$. linteus was $2.9^{\circ} \mathrm{C}$ lower in the SSF system than in the SLF system due to the different cultivation characteristics. In general, metabolic heat generated by microbial activity is difficult to dissipate in SSF systems (Raghavarao et al., 2003). In fact, active fungal growth can generate a rapid temperature gradient (i.e., $3.0^{\circ} \mathrm{C} / \mathrm{cm}$ ) 
(a)
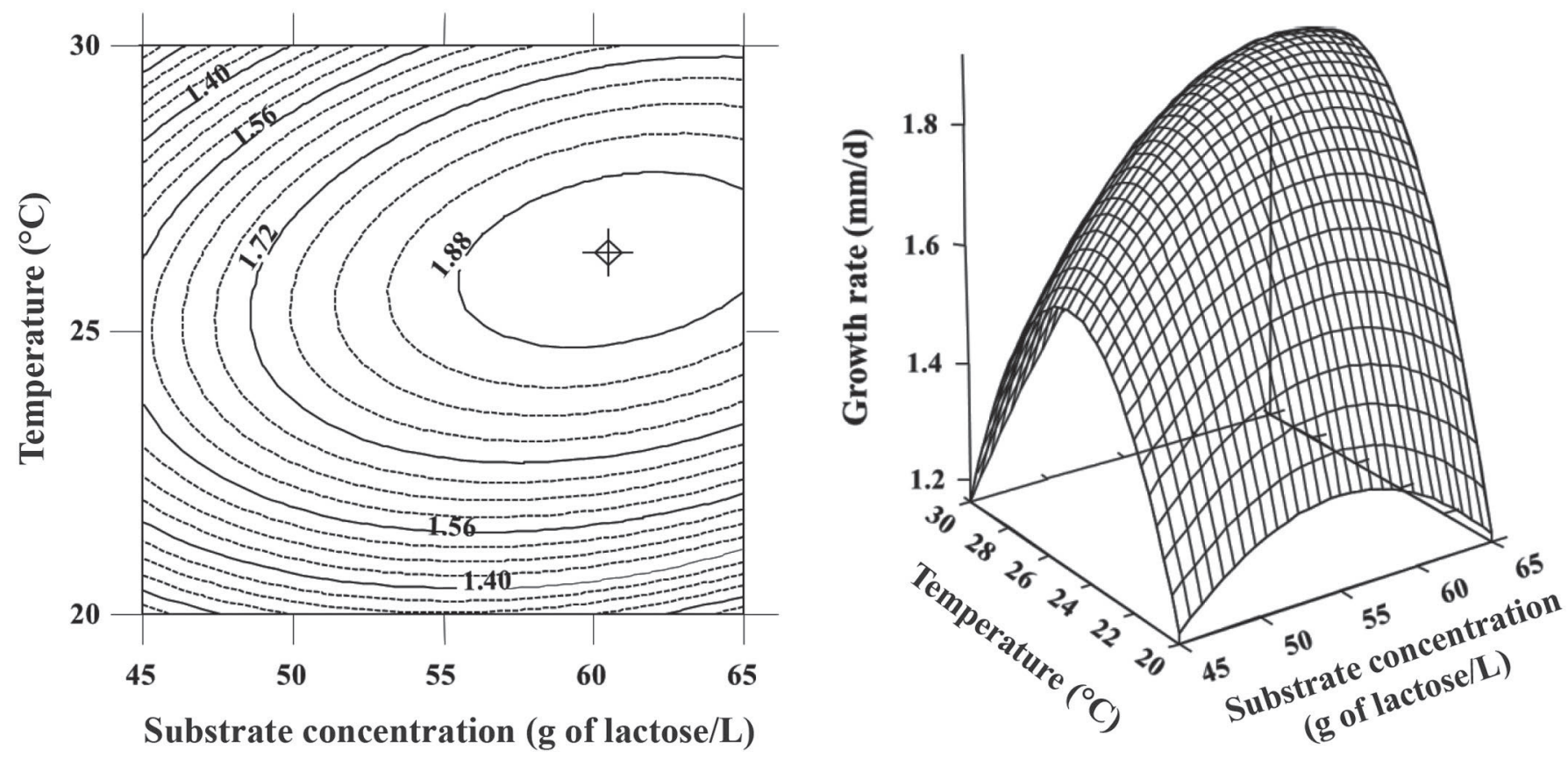

(b)
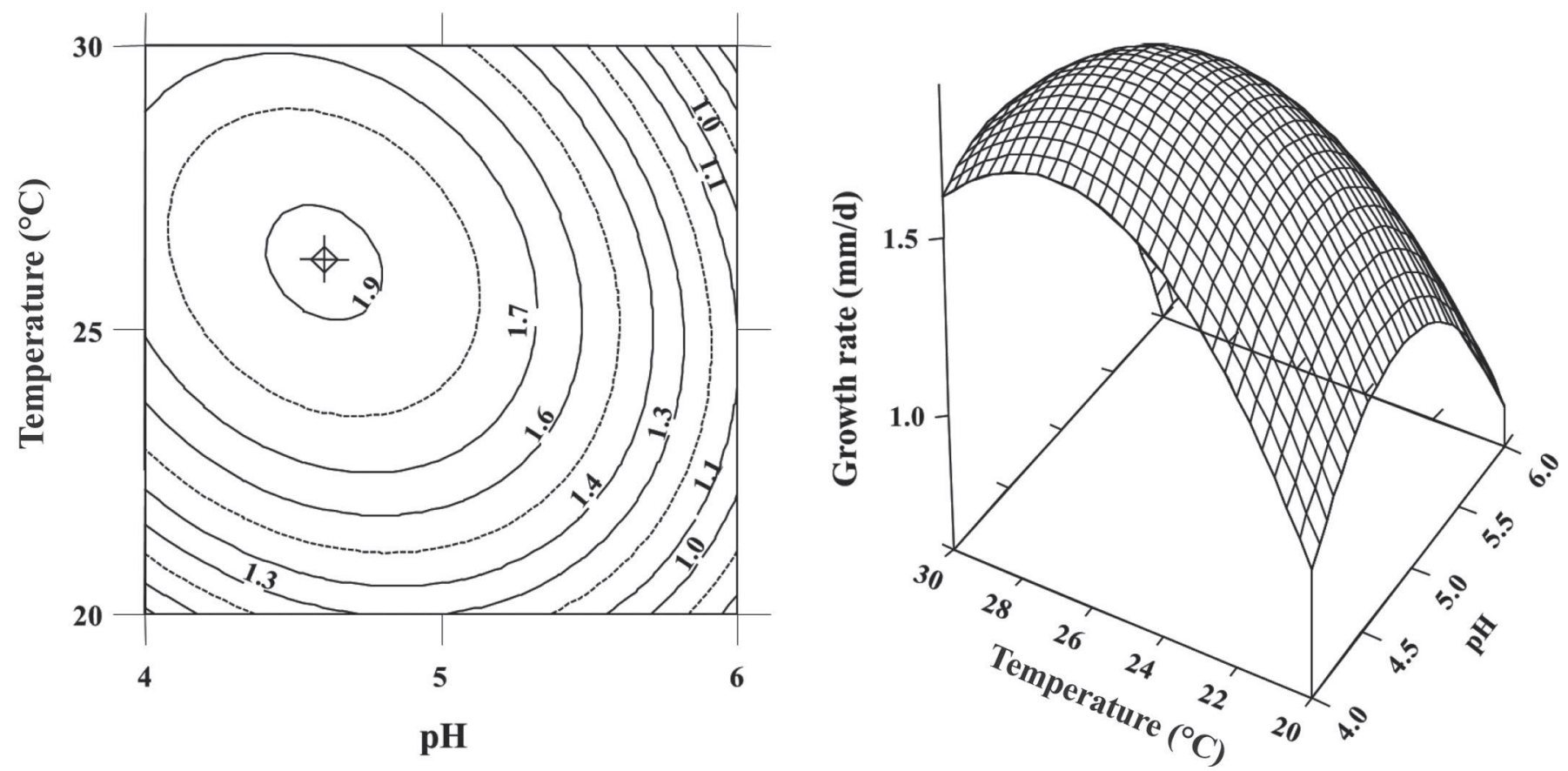

Figure 2. Two- and 3-dimensional contour plots of the models for the growth rates of Phellinus linteus mycelia in the solid-state fermentation (SSF) system with respect to (a) temperature and substrate concentration and (b) temperature and $\mathrm{pH}$ within the design boundaries. 
Table 3. Results of ANOVA for independent variables

\begin{tabular}{|c|c|c|c|c|c|c|}
\hline Term & \multicolumn{3}{|c|}{ Solid-state fermentation system } & \multicolumn{3}{|c|}{ Submerged liquid fermentation system } \\
\hline Temperature & 0.254 & 2 & 0.006 & $3,599.1$ & 2 & 0.002 \\
\hline Substrate concentration & 0.061 & 2 & 0.164 & $8,034.6$ & 2 & $<0.001$ \\
\hline Temperature $\times \mathrm{pH}$ & 0.285 & 1 & 0.010 & 144.5 & 1 & 0.521 \\
\hline Temperature $\times$ substrate concentration & 0.143 & 1 & 0.048 & $9,773.4$ & 1 & $<0.001$ \\
\hline
\end{tabular}

in solid-type cultures (Lonsane et al., 1985). Therefore, the retained metabolic heat in the SSF system may have reduced the optimum $T_{\mathrm{O}}$ for growth of mycelial $P$. linteus. The results suggest that the SSF system should be operated at lower $T_{\mathrm{O}}$ than the SLF system during bioconversion operation using $P$. linteus.

In addition, $T_{\mathrm{O}}$ significantly affected the growth of $P$. linteus in both fermentation systems (Figures 2 and 4) because temperature is a critical factor that directly affects microbial activity (Madigan et al., 2008). The significant effect of temperature on the growth is clearly reflected in Figures 2 and 4, where the responses demonstrate considerable change along with the temperature axis. For example, when $T_{\mathrm{O}}$ decreased from the optimum condition to $20.0^{\circ} \mathrm{C}$, mycelial growth rates decreased by $37 \%$ in SSF and by $42 \%$ in SLF. Therefore, $T_{\mathrm{O}}$ must be strictly controlled when cultivating mycelial $P$. linteus in whey permeate wastewater, regardless of fermentation method.

The effect of initial $\mathrm{pH}$ on mycelial growth rate was statistically significant at the $1 \% \alpha$-level for the SSF system but insignificant at the $5 \%$-level for the SLF

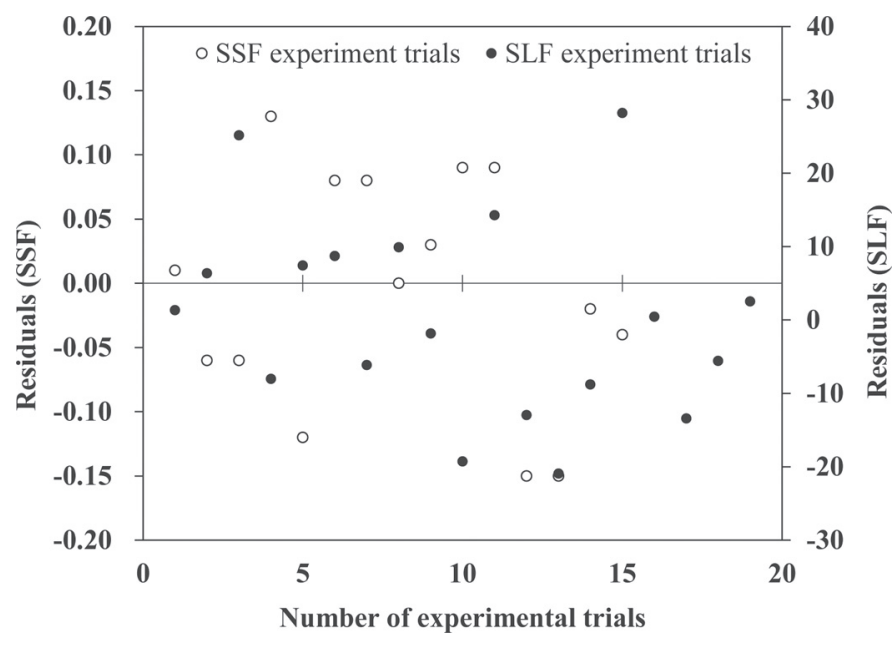

Figure 3. Residual plots of the evaluated models for the solid-state fermentation (SSF; O) and submerged liquid fermentation (SLF; systems. system (Figure 2, Table 3). In fact, the growth rate of $P$. linteus mycelium varied considerably with the change of initial $\mathrm{pH}$ in the SSF system only (Figure 2 ). The optimal initial $\mathrm{pH}$ values in both systems were similar to that reported in a previous study $-\mathrm{pH} 5.0$ (Kim et al., 2001). However, the optimum growth $\mathrm{pH}$ of $P$. linteus is controversial. In fact, Lee et al. (2008b) reported that the mycelial $P$. linteus grew optimally at pH 6.0 in starch wastewater medium (Lee et al., 2008b). The difference might be related to the difference of extracellular enzymes and their activity in ambient $\mathrm{pH}$ conditions. In the present study, P. linteus might secrete an extracellular enzyme, $\beta$-D-galactosidase, which degrades the lactose to soluble substrate that can pass though the cell wall. In fact, the optimum $\mathrm{pH}$ range of $\beta$-D-galactosidase is $\mathrm{pH} 3.8$ to 5.2 , which covers the optimal growth $\mathrm{pH}$ of $P$. linteus in this study (Macris and Markakis, 1981). In contrast, the optimal growth $\mathrm{pH}$ of the previous study, $\mathrm{pH}$ 6.0, corresponded to the optimum $\mathrm{pH}$ range (i.e., $\mathrm{pH} 5.2$ to 6.9 ) of $\alpha$-amylase, which degrades starch to soluble sugars (Ishikawa et al., 1990; Lee et al., 2008b). Therefore, the optimum growth $\mathrm{pH}$ at the SSF and the SLF systems may be determined by the unique substrate characteristic of the whey permeate wastewater; that is, the lactose richness.

The difference between the SSF and the SLF systems of the optimal growth $\mathrm{pH}$ and its significance could have 3 causes: (1) pH decrease in the cultivation medium due to the actions of extracellular enzymes, (2) the hyphal growth characteristic of mycelia, and (3) the different mixing properties of the fermentation systems. During fermentation, fungi secrete extracellular enzymes to hydrolyze particular substrates; this process decreases the $\mathrm{pH}$ in the growth medium, and ultimately generates a $\mathrm{pH}$ gradient in the cultivation system (Mitchell et al., 2000). Interestingly, the actively growing tip of a mycelial hypha can overcome severe ambient conditions such as local $\mathrm{pH}$ decrease and substrate depletion in SSF systems, because the active tip of the hypha extends to intake the substrate (Riquelme, 2013; Sanati Nezhad and Geitmann, 2013). This ability implies that 
(a)

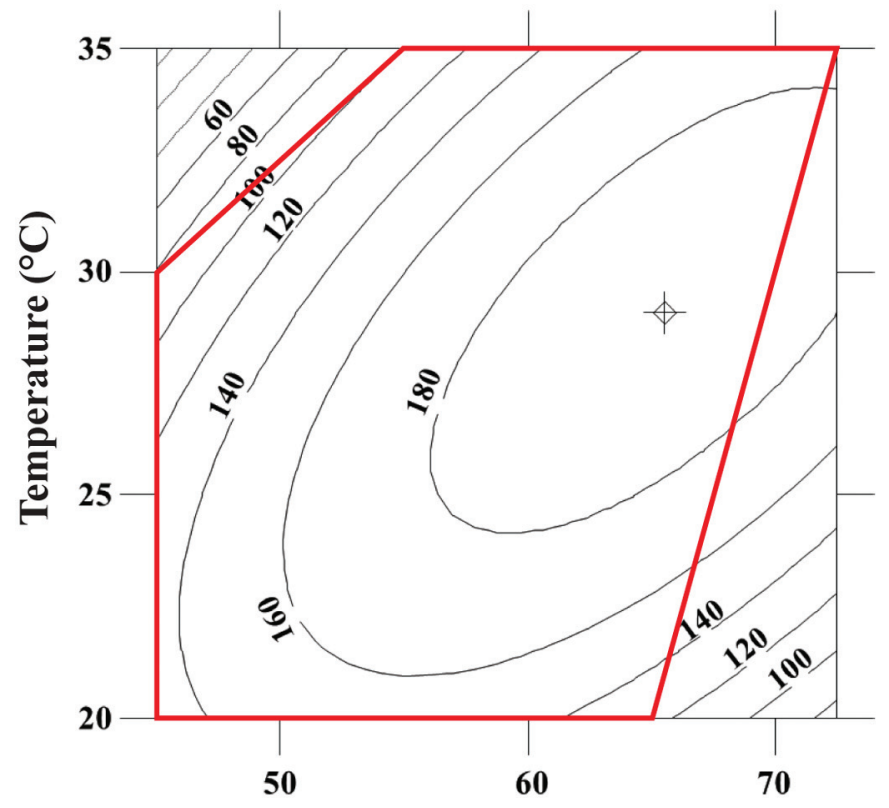

Substrate concentration (g of lactose/L)

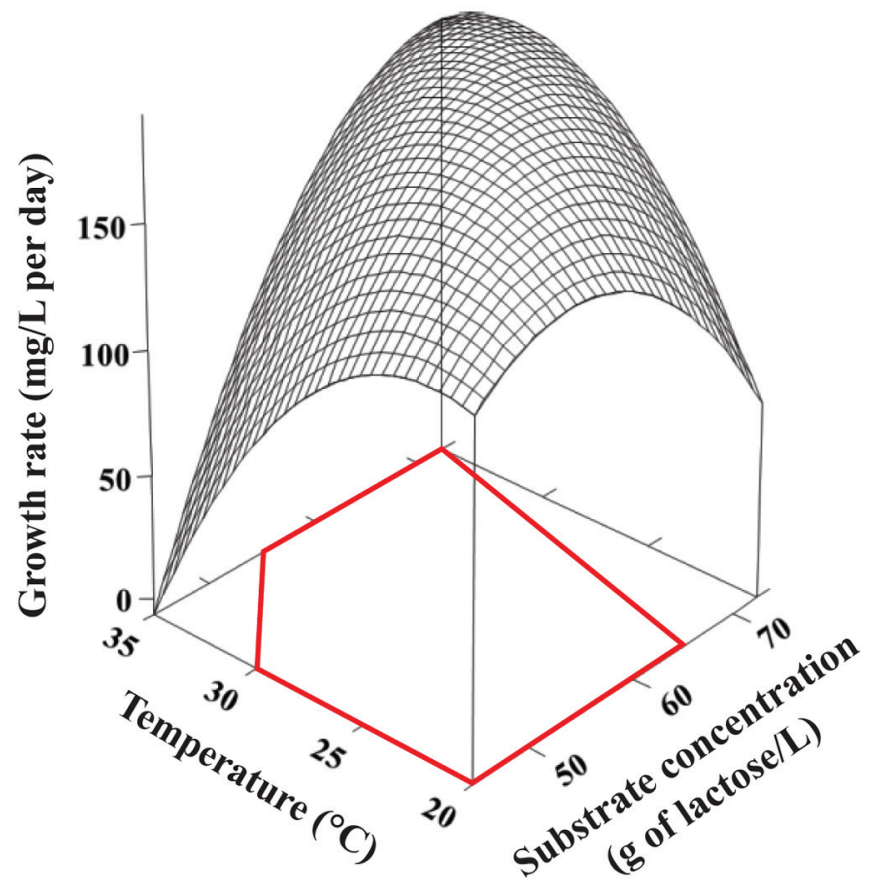

(b)
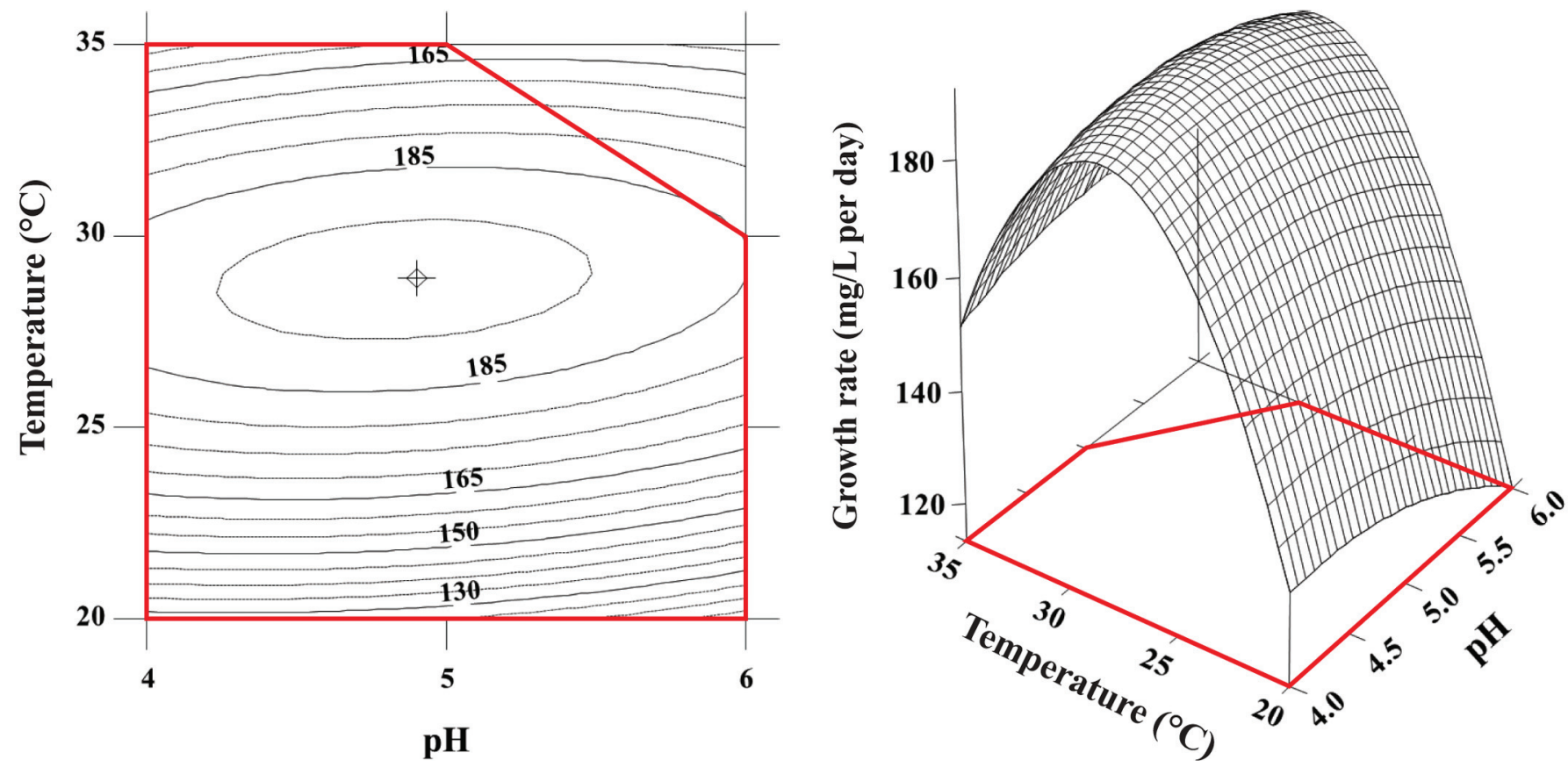

Figure 4. Two- and 3-dimensional contour plots of the models for the growth rates of Phellinus linteus mycelia in the submerged liquid fermentation system with respect to (a) temperature and substrate concentration, and (b) temperature and $\mathrm{pH}$ within the design boundaries. The dashed linear (red) lines on the contour plots were based on the ranges of the independent variables described in Table 2 and represent the boundary conditions to calculate the growth rate using the evaluated models. Color version available online. 
the hyphal tip of $P$. linteus may have contacted fresh substrate that was at constant $\mathrm{pH}$; that is, initial $\mathrm{pH}$ directly affected the growth $\mathrm{pH}$ of the mycelia. However, in SLF systems, the $\mathrm{pH}$ decreases in the entire medium due to mixing, so that $P$. linteus mycelia can be exposed to varied $\mathrm{pH}$. This implies that the initial $\mathrm{pH}$ would have relatively little effect on the growth of $P$. linteus mycelia in SLF. This argument may explain why the effect of initial $\mathrm{pH}$ on growth of mycelial $P$. linteus was more significant in the SSF system than in the SLF system (Table 3, Figure 2). These observations suggest that control of initial $\mathrm{pH}$ enhances the process stability of SSF for mycelial bioconversion utilizing whey permeate wastewater. Moreover, in the same context, the optimal initial $\mathrm{pH}$ may have been higher in the SLF system than in the SSF system because extracellular enzymes might reduce the $\mathrm{pH}$ over time. The results indicate that initial $\mathrm{pH}$ has different effects on the growth of $P$. linteus mycelia despite the use of the same substrate.

The optimal $[S]$ was $60.3 \mathrm{~g}$ of lactose/L for the SSF system and $65.3 \mathrm{~g}$ of lactose/L for the SLF system, but it had a significant effect on mycelial growth only in the SSF system (Table 3, Figure 2). These values are about twice as high as the optimal substrate concentration of $29.7 \mathrm{~g}$ of lactose/L when using cheese whey as a sole substrate for cultivation of the mycelial $P$. linteus in an SSF system (Lee et al., 2011). In general, whey permeate is generated by ultrafiltration of raw cheese whey; this process removes whey proteins that enhance microbial growth (i.e., $\beta$-LG, BSA, $\alpha$-LA, and so on; Singh et al., 2014), so whey permeate wastewater contains fewer nutrients than does cheese whey; this deficiency explains why higher $[S]$ was required for optimal growth of mycelial $P$. linteus in our study than when whey was used. This hypothesis could be tested by reducing permeate loading or adding whey proteins in further research.

The differences in the optimum $[S]$ and in the significance of $[S]$ between the systems could be caused by the different substrate delivery characteristics - diffusion for SSF and mixing for SLF. In principle, diffusivity is significantly affected by the distance $D$ between the microorganism and the source of the substrate that determines its growth rate (Harms and Bosma, 1997; Gonzo et al., 2014), so growth rate is inversely related to $D$. Several previous studies reported that the microbial activity depends on $D$ (Harms and Bosma, 1997; Knudsen et al., 2013). In addition, during growth of filamentous fungi in SSF systems, hyphae penetrate the solid substrate matrix, so extracellular enzymes can reach deeply into it (Barrios-Gonzalez, 2012); this hyphal penetration enhances the substrate diffusivity by reducing $D$ (Mitchell et al., 2000). However, in SLF sys- tems, substrate is delivered mainly by mixing, which is a different mechanism than occurs in the SSF systems. This unique property can decrease substrate uptake by fungi in SLF systems. For example, the turbulent current generated by mixing can hinder substrate uptake by disturbing relevant contact between the substrate and fungi (Raghavarao et al., 2003). In addition, the shear force created by agitation can damage the hyphae, and thereby cause variation in growth rate (Tang et al., 2007). Therefore, these comparisons suggest that $P$. linteus mycelia can efficiently utilize the substrate despite the low $[S]$ in the SSF system, so the optimal growth rate can be achieved at lower $[S]$ in the SSF system than in the SLF system. Moreover, $[S]$ would not have a significant effect on mycelial growth the SSF system because substrate utilization efficiency can be high regardless of $[S]$ due to hyphal penetration into the substrate. However, $[S]$ would significantly affect the growth rate in the SLF system due to mixing (Figure 4). Therefore, the results suggest that $[S]$ should be carefully controlled in SLF systems for cultivating $P$. linteus.

\section{CONCLUSIONS}

This study evaluated the use of whey permeate wastewater medium as a sole nutrient source for cultivation of $P$. linteus mycelia in SSF and SLF systems. Optimal growth conditions were $T_{\mathrm{O}}=26.1^{\circ} \mathrm{C}, \mathrm{pH}=4.6$, and $[S]=60.3 \mathrm{~g}$ of lactose/L in the SSF system and $T_{\mathrm{O}}=$ $29.0^{\circ} \mathrm{C}, \mathrm{pH}=5.0$, and $[S]=65.3 \mathrm{~g}$ of lactose $/ \mathrm{L}$ in the SLF system. Operating temperature had a statistically significant effect on growth rates in both fermentation systems; initial $\mathrm{pH}$ (but not $[S]$ ) was significant in the SSF system, whereas $[S]$ (but not initial $\mathrm{pH}$ ) was significant in the SLF system. These findings can be used to guide operation of processes to cultivate $P$. linteus mycelia using whey permeate wastewater.

\section{ACKNOWLEDGMENTS}

This work was supported by the Human Resources Development of the Korea Institute of Energy Technology Evaluation and Planning (KETEP) granted financial resource from the Korea government Ministry of Trade, Industry \& Energy (No. 20144030200460) and by Korea Ministry of Environment (Seoul) as "Human Resource Development Project for Energy from Waste \& Recycling."

\section{REFERENCES}

Akbas, M. Y., T. Sar, and B. Ozcelik. 2014. Improved ethanol production from cheese whey, whey powder, and sugar beet molasses 
by "Vitreoscilla hemoglobin expressing" Escherichia coli. Biosci. Biotechnol. Biochem. 78:687-694.

APHA-AWWA-WEF [American Public Health Association (APHA), the American Water Works Association (AWWA), and the Water Environment Federation (WEF)]. 2005. Standard Methods for the Examination of Water and Wastewater. 21st ed. American Public Health Association, Washington, DC.

Barrios-Gonzalez, J. 2012. Solid-state fermentation: Physiology of solid medium, its molecular basis and applications. Process Biochem. $47: 175-185$.

Carvalho, F., A. R. Prazeres, and J. Rivas. 2013. Cheese whey wastewater: Characterization and treatment. Sci. Total Environ. 445446:385-396.

Dallas, D. C., V. Weinborn, J. M. L. N. de Moura Bell, M. Wang, E. A. Parker, A. Guerrero, K. A. Hettinga, C. B. Lebrilla, J. B. German, and D. Barile. 2014. Comprehensive peptidomic and glycomic evaluation reveals that sweet whey permeate from colostrum is a source of milk protein-derived peptides and oligosaccharides. Food Res. Int. 63(B):203-209.

Diamantis, V. I., A. G. Kapagiannidis, S. Ntougias, V. Tataki, P. Melidis, and A. Aivasidis. 2014. Two-stage CSTR-UASB digestion enables superior and alkali addition-free cheese whey treatment. Biochem. Eng. J. 84:45-52.

DuBois, M., K. A. Gilles, J. K. Hamilton, P. A. Rebers, and F. Smith. 1956. Colorimetric method for determination of sugars and related substances. Anal. Chem. 28:350-356.

Gonzo, E. E., S. Wuertz, and V. B. Rajal. 2014. The continuum heterogeneous biofilm model with multiple limiting substrate Monod kinetics. Biotechnol. Bioeng. 111:2252-2264.

Harms, H., and T. N. P. Bosma. 1997. Mass transfer limitation of microbial growth and pollutant degradation. J. Ind. Microbiol. Biotechnol. 18:97-105.

Hatvani, N., and I. Mećs. 2001. Production of laccase and manganese peroxidase by Lentinus edodes on malt-containing by-product of the brewing process. Process Biochem. 37:491-496.

Hwang, H.-J., S.-W. Kim, J.-W. Choi, and J.-W. Yun. 2003. Production and characterization of exopolysaccharides from submerged culture of Phellinus linteus KCTC 6190. Enzyme Microb. Technol. 33:309-319.

Ishikawa, K., I. Matsui, K. Honda, and H. Nakatani. 1990. Substratedependent shift of optimum $\mathrm{pH}$ in porcine pancreatic alpha-amylase-catalyzed reactions. Biochemistry 29:7119-7123.

Kim, D. H., B. K. Yang, S. C. Jeong, J. B. Park, S. P. Cho, S. Das, J. W. Yun, and C. H. Song. 2001. Production of a hypoglycemic, extracellular polysaccharide from the submerged culture of the mushroom, Phellinus linteus. Biotechnol. Lett. 23:513-517.

Knudsen, B. E., L. Ellegaard-Jensen, C. N. Albers, S. Rosendahl, and J. Aamand. 2013. Fungal hyphae stimulate bacterial degradation of 2,6-dichlorobenzamide (BAM). Environ. Pollut. 181:122-127.

Lee, C., S. Lee, K. J. Cho, and S. Hwang. 2011. Mycelial cultivation of Phellinus linteus using cheese-processing waste and optimization of bioconversion conditions. Biodegradation 22:103-110.

Lee, H., M. Song, Y. Yu, and S. Hwang. 2003. Production of Ganoderma lucidum mycelium using cheese whey as an alternative substrate: response surface analysis and biokinetics. Biochem. Eng. J. $15: 93-99$.

Lee, S., H. Bae, N. Kim, and S. Hwang. 2008a. Optimization of growth conditions of Lentinus edodes mycelium on corn processing waste using response surface analysis. J. Biosci. Bioeng. 105:161-163.

Lee, S., H. Bae, M. Song, and S. Hwang. 2008b. Bioconversion of starch processing waste to Phellinus linteus mycelium in solid-state cultivation. J. Ind. Microbiol. Biotechnol. 35:859-865.
Liang, C.-H., J.-L. Syu, and J.-L. Mau. 2009. Antioxidant properties of solid-state fermented adlay and rice by Phellinus linteus. Food Chem. 116:841-845.

Lonsane, B. K., N. P. Ghildyal, S. Budiatman, and S. V. Ramakrishna. 1985. Engineering aspects of solid-state fermentation. Enzyme Microb. Technol. 7:258-265.

Macris, B. J., and P. Markakis. 1981. Characterization of extracellular $\beta$-D-galactosidase from Fusarium moniliforme grown in whey. Appl. Environ. Microbiol. 41:956-958.

Madigan, M. T., J. M. Martinko, P. V. Dunlap, and D. P. Clark. 2008. Brock Biology of Microorganisms. 12th ed. Benjamin Cummings, Menlo Park, CA.

Mei, Y., H. Zhu, Q. Hu, Y. Liu, S. Zhao, N. Peng, and Y. Liang. 2015. A novel polysaccharide from mycelia of cultured Phellinus linteus displays antitumor activity through apoptosis. Carbohydr. Polym. 124:90-97.

Mitchell, D., M. Berovic, and N. Krieger. 2000. Biochemical engineering aspects of solid state bioprocessing. Pages $61-138$ in New Products and New Areas of Bioprocess Engineering. Vol. 68. Springer Berlin, Germany.

Pais, J., I. Farinha, F. Freitas, L. S. Serafim, V. Martinez, J. Carlos Martinez, M. Arevalo-Rodriguez, M. Auxiliadora Prieto, and M. A. M. Reis. 2014. Improvement on the yield of polyhydroxyalkanotes production from cheese whey by a recombinant Escherichia coli strain using the proton suicide methodology. Enzyme Microb. Technol. 55:151-158.

Raghavarao, K., T. V. Ranganathan, and N. G. Karanth. 2003. Some engineering aspects of solid-state fermentation. Biochem. Eng. J. $13: 127-135$.

Riquelme, M. 2013. Tip growth in filamentous fungi: A road trip to the apex. Annu. Rev. Microbiol. 67:587-609.

Sanati Nezhad, A., and A. Geitmann. 2013. The cellular mechanics of an invasive lifestyle. J. Exp. Bot. 64:4709-4728.

Sansonetti, S., S. Curcio, V. Calabrò, and G. Iorio. 2009. Biol.-ethanol production by fermentation of ricotta cheese whey as an effective alternative non-vegetable source. Biomass Bioenergy 33:16871692

Shi, X. M., H. J. Liu, X. W. Zhang, and F. Chen. 1999. Production of biomass and lutein by Chlorella protothecoides at various glucose concentrations in heterotrophic cultures. Process Biochem. 34:341-347.

Shuler, M. L., and F. Kargi. 2001. Bioprocess Engineering Basic Concepts. 2nd ed. Prentice Hall International Series, Upper Saddle River, NJ.

Singh, S., P. Khemariva, and A. Rai. 2014. Process optimization for the manufacture of lemon based beverage from hydrolyzed whey. J. Food Sci. Technol. 51:691-699.

Singhania, R. R., A. K. Patel, C. R. Soccol, and A. Pandey. 2009. Recent advances in solid-state fermentation. Biochem. Eng. J. 44:13-18.

Song, M., N. Kim, S. Lee, and S. Hwang. 2007. Use of whey permeate for cultivating Ganoderma lucidum mycelia. J. Dairy Sci 90:2141-2146

Tang, Y. J., L. W. Zhu, H. M. Li, and D. S. Li. 2007. Submerged culture of mushrooms in bioreactors - Challenges, current state-ofthe-art, and future prospects. Food Technol. Biotechnol. 45:221229 . 